\title{
An Uncertain Optimization Model for Low- Carbon Product Family Design
}

\author{
Qi Wang ${ }^{\mathrm{a}, \mathrm{b}, \mathrm{c}}$ and Peipei $\mathrm{Qi}^{\mathrm{d} 1}$ \\ ${ }^{a}$ School of Mechanical and Energy Engineering, NingboTech University, Ningbo \\ 315100, China \\ ${ }^{\mathrm{b}}$ College of Mechanical and Electrical Engineering, Nanjing University of Aeronautics \\ and Astronautics, Nanjing 210016, China \\ ${ }^{\mathrm{c} J i a n g s u}$ Ankao intelligent transmission engineering technology Co., Ltd, Liyang, \\ 213332, China \\ ${ }^{\mathrm{d}}$ College of Wealth management, Ningbo University of Finance \& Economics, Ningbo, \\ 315175, China
}

\begin{abstract}
Global warming has attracted more and more people's attention. Since products are one of the main sources of GHG emission, the firm is seeking appropriate methods to reduce GHG emission of the product. At present, product family design is widely adopted for meeting the various demand of customers. To reduce the GHG emission of products, some methods have been proposed for lowcarbon product family design in recently years. In existing research, the related data of low-carbon product family design is given as crisp value. However, in a real environment, some design data can't be assessed accurately. To this end, this paper proposes a uncertain optimization model for low-carbon product family design. In the model, the related uncertain data for low-carbon product family design is given as interval numbers. Based on the objective of profit and GHG emission, the model can simultaneously determine product family configuration, supplier selection and price strategies of product variants. In addition, the genetic algorithm is developed to solve the established model. Finally, a case study is performed to demonstrate the effectiveness of the proposed approach.
\end{abstract}

Keywords. Low-carbon design,Modular product family design,Green design

\section{Introduction}

Intergovernmental Panel on Climate Change indicates that human-made GHG emission cause of global warming [1]. To reducing GHG emission, many countries have issued relevant policies to encourage enterprises to manufacture low-carbon products, such as ISO 14064, PAS 2050, and ISO/TS 14067. At present, low-carbon product design has received more and more attention from academia and industry. For example, Song et al. [2] developed a system using the bill of materials to design a low-carbon product. Su et al. [3] proposed an approach to assess the carbon emission and the cost in conceptual product design. Kuo et al. [4] reported an optimization method for low-carbon product design considering cost, supplier capacity, and component transport. Xu et al. [5] built a low-carbon product multi-objective optimization approach to deal with the contradiction

\footnotetext{
${ }^{1}$ Corresponding Author.
} 
among the firm, consumers, and governments. Chiang et al. [6] investigated a method to develop a low-carbon electronic product. Zhang et al. [7] presented a hybrid low-carbon optimization model for design structural components considering material selection, structure layout, and structure parameters. These methods are oriented to a single lowcarbon product design. To meet the diversified

needs of customers, the product family design with multiple product variants has been widely adopted in recent years. Since the design of product variants included in the product family are interrelated, the low-carbon design approach for a single product is not suitable for low-carbon product family design. To this end, some researchers began to study the low-carbon design method for product family. For example, Kim et al. [8] studied an approach to identify a sustainable platform. Wang et al. [9] proposed a model to the simultaneously optimization of low-carbon design of product family and remanufactured products. Wang et al. [10] presented a method for modular product family design considering cost and GHG emission. Xiao et al. [11] gave a method for collaborative optimization of product family design and manufacturing process planning. Since supplier selection affects both the production cost of the product and the GHG emission of the product, Wang et al. [12] presented an optimization model to simultaneously optimization supplier selection and low-carbon design of the product family. Although some studies have discussed the low-carbon product family design, the related design data is considered as a crisp value. However, in a realistic environment, some data is only given as an interval number rather than a crisp value due to the uncertainty of design information. To solve the above-mentioned problems, this article proposes a uncertain optimization model for low-carbon product family design. Moreover, the genetic algorithm is developed for obtaining the optimal solution.

The structure of this article is as follows. In Section 2, the problem is described. An uncertain optimization model is established in Section 3. Section 4 addresses the solution algorithm for solving the optimization model. To demonstrate the benefits of the proposed approach, a case study is given in Section 5. Section 6 is the summary.

\section{Problem description}

The optimization problem is described as follows: a product is developed into a modular architecture, that is, a product can be considered to be composed of a group of function modules. For meeting the diverse needs of customers, the company plans to develop a product family. In this article, supposing that module instances are provided by external suppliers, and the main company assembles product. Several types of module instances can be supplied by one supplier. Different suppliers offer different discount schemes. The purpose of this article is to simultaneously optimize the module instance configuration of all product variants included in the product family, supplier selection and selling price of each product variant based on the objectives of maximizing profit and minimizing GHG emission of the product family.

The decision variables are defined as follows: 
$y_{g h}^{(f)}=\left\{\begin{array}{l}1 \text { if } h \text { th instance of } g \text { th module }\left(\mathrm{M}_{g, h}\right) \text { is used to configure to the } f \text { th product variant } \\ \quad(g=1,2, \ldots, G ; h=1,2 \ldots, H ; f=1,2, \ldots, F) \\ 0 \text { otherwise }\end{array}\right.$ $x_{g h}^{(f) z}=\left\{\begin{array}{c}1 \text { if } h \text { th instance of } g \text { th module }\left(M_{g, h}\right) \text { for the } f \text { th product variant is provided by } z \text { th supplier } \\ (g=1,2, \ldots, G ; h=1,2 \ldots, H ; f=1,2, \ldots, F ; z=1,2 \ldots, Z) \\ 0 \text { otherwise }\end{array}\right.$ $p_{f}:$ the price of $f$ thproduct variant $(f=1,2 \ldots, F)$

\section{Establishment of uncertain optimization model}

\subsection{Customer preference model}

The product market is divided into several market segments in advance, and the size of each market segment is also estimated. In this article, the customer preference model is established based on the utility function. According to the part-worth model [13], the utility of the $f$ th product variant in the $m$ th market segment is calculated as follows:

$$
U_{p r o}^{f(m)}=\sum_{g=1}^{G} \sum_{h=1}^{H} y_{g h}^{(f)}\left[\mu_{g h}^{(m)-L}, \mu_{g h}^{(m)-R}\right]+\eta_{r}
$$

where $\left[\mu_{g h}^{(m)-L}, \mu_{g h}^{(m)-R}\right]$ is an interval number, representing the possible utility of module instance $\mathrm{M}_{\mathrm{g}, \mathrm{h}}$ in the $m$ th market segment, $\eta_{r}$ is a constant.

Taking into account the selling price of the product, the surplus utility of $f$ th product variant in the $m$ th market segment $\left(\lambda^{f(m)}\right)$ is evaluated as:

$$
\lambda^{f(m)}=U_{p r o}^{f(m)}-p_{f}
$$

where $p_{f}$ is the the selling price of $f$ th product variant.

\subsection{Market demand of products and expected revenue}

Customers' decision to buy a product is not only affected by the surplus utility of the product but also other similar products. The probabilistic choice rule can well express this situation. In the probabilistic choice rule, the multinomial logit choice (MNL) rule is adopted in this research. According to the MNL rule, the probability of the $f$ th product variant selected in the $m$ th market segment $\left(P_{f}^{(m)}\right)$ is calculated as follows:

$$
P_{f}^{(m)}=\frac{e^{\delta \lambda^{f(m)}}}{\sum_{f=1}^{F} e^{\delta \lambda^{f(m)}}+\sum_{e=1}^{E} e^{\delta\left[\lambda^{e(m)-L}, \lambda^{e(m)-L}\right]}}
$$

where $E$ represents the number of similar products launched by other companies. $\left[\lambda^{e(m)-L}, \lambda^{e(m)-R}\right]$ is the possible surplus utility of $e$ th similar product in the $m$ th market segment.

The demand of $f$ th product variant in the $m$ th market segment $\left(Q_{f}^{(m)}\right)$ is expressed as follows:

$$
Q_{f}^{(m)}=n_{m} P_{f}^{(m)}
$$

where $n_{\mathrm{m}}$ is the total the demand in the $m$ th market segment. 
The expected revenue $\left(R_{\mathrm{to}}\right)$ is estimated as follows:

$$
R_{t o}=\sum_{m=1}^{M} \sum_{f=1}^{F} Q_{f}^{(m)} p_{f}
$$

\subsection{Production cost of a product family}

The cost $(\mathrm{C})$ is divided into the production cost within the enterprise $\left(C^{\text {within }}\right)$ and external procurement $\operatorname{cost}\left(C^{\text {pro }}\right)$, and it is formulated as:

$$
C=C^{\text {within }}+C^{\text {pro }}
$$

$C^{\text {within }}$ is consists of the fixed cost $\left(C^{\text {within(fix) }}\right)$ and the variable cost $\left(C^{\text {within(var) }}\right) . C^{\text {within(fix) }}$ includes the development cost, management cost, etc., and it is related to the number of product variants developed. Assuming that $k$ product variants are developed, the $C^{\text {within(fix) }}$

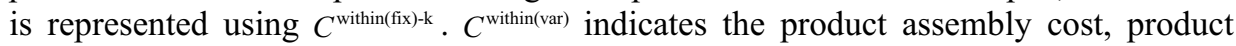
packaging cost, etc, and it is expressed as:

$$
C^{\mathrm{with}(\mathrm{var})}=\sum_{m=1}^{M} \sum_{f=1}^{F} \sum_{g=1}^{G} \sum_{h=1}^{H} Q_{f}^{(m)}\left[c_{g h}^{\mathrm{with}(\mathrm{var})-\mathrm{L}}, c_{g h}^{\mathrm{with}(\mathrm{var})-\mathrm{R}}\right] y_{g h}^{(f)}
$$

where $\left[c_{g h}^{\text {within(var)-L }}, c_{g h}^{\text {within(var)-R }}\right]$ is an interval number, and it represents the possible unit variable production cost of $\mathrm{M}_{\mathrm{g}, \mathrm{h}}$.

$C^{p \text { ro }}$ also divided into the fix cost of using suppliers $\left(C^{\text {profix) }}\right)$ and the variant cost $\left(C^{\mathrm{pro}(\mathrm{var})}\right)$.

$C^{\text {prof(ix) }}$ represents the negotiation cost, and so on, and it is expressed as:

$$
C^{\text {pro(fix) }}=\sum_{z=1}^{Z}\left[E_{z}^{L}, E_{z}^{R}\right] G_{z}
$$

where $\left[E_{z}^{L}, E_{z}^{R}\right]$ represents the fixed cost of selection the $z$ th supplier, $G_{z}$ is 1 when the zth supplier is adopted, otherwise, $G_{z}$ is 0 .

$C^{\text {pro(var) }}$ indicates purchasing cost and transportation cost, and it can be formulated as follows:

$$
C^{\mathrm{out}(\mathrm{var})}=\sum_{z=1}^{Z}\left[\sum_{g=1}^{G} \sum_{h=1}^{H} \sum_{m=1}^{M} \sum_{f=1}^{F} Q_{f}^{(m)} y_{g h}^{(f)} N_{g h}^{z} p_{g h}^{z}\right]\left(1-\delta_{z}\right)+\sum_{z=1}^{Z}\left[\sum_{g=1}^{G} \sum_{h=1}^{H} \sum_{m=1}^{M} \sum_{f=1}^{F} Q_{f}^{(m)} y_{g h}^{(f)} x_{g h}^{(f) z} m_{g h}^{z}\right] S^{z}\left[C_{T r}^{L}, C_{T r}^{R}\right]
$$

where $p_{g h}^{z}$ represents the purchase price of $\mathrm{M}_{\mathrm{g}, \mathrm{h}}$ provided by the $z$ th supplier, $\delta_{z}$ is the discount rate provided by the zth supplier, $m_{g h}^{z}$ indicates the weight of $\mathrm{M}_{\mathrm{g}, \mathrm{h}}$ provided by the $z$ th supplier, $S z$ represents the distance from the $z$ th supplier to the assembly firm, $\left[C_{T r}^{L}, C_{T r}^{R}\right]$ represents the possible unit transportation cost.

\subsection{Greenhouse gas emission model of a product family}

The total GHG emission $E_{\mathrm{T}}$ is divided into four parts, including the GHG emission from component $\left(E_{c o m}^{T}\right)$, transportation $\left(E_{\text {tra }}^{T}\right)$, production within the enterprise $\left(E_{p r o}^{T}\right)$ and supplier selection $\left(E_{\text {sup }}^{\text {sel }}\right) . E_{\mathrm{T}}$ is expressed as:

$$
E^{T o}=E_{c o m}^{T}+E_{\text {tra }}^{T}+E_{\text {pro }}^{T}+E_{\text {sup }}^{\text {sel }}
$$

$E_{c o m}^{T}$ is formulated as follows:

$$
E_{c o m}^{T}=\sum_{g=1}^{G} \sum_{h=1}^{H} \sum_{m=1}^{M} \sum_{f=1}^{F} Q_{f}^{(m)} y_{g h}^{(f)}\left[e_{g h}^{z-L}, e_{g h}^{z-R}\right]
$$


where $\left[e_{g h}^{z-L}, e_{g h}^{z-R}\right]$ is an interval number, and it represents the possible GHG emission for module instance $\mathrm{M}_{\mathrm{g}, \mathrm{h}}$ provided by $\mathrm{z}$ th supplier.

The GHG emission from transportation can be described as follows:

$$
E_{\text {tra }}^{T}=\sum_{z=1}^{Z} \sum_{g=1}^{G} \sum_{h=1}^{H} \sum_{m=1}^{M} \sum_{f=1}^{F} Q_{f}^{(m)} y_{g h}^{(f)} x_{g h}^{z(f)} m_{g h}^{z} S^{z}\left[E_{T r}^{L}, E_{T r}^{R}\right]
$$

where $\left[E_{T r}^{L}, E_{T r}^{R}\right]$ is an interval number, and it indicates the possible unit transportation GHG emission.

$E_{p r o}^{T}$, including fixed emission $\left[E_{p r o}^{f i x(V)-L}, E_{p r o}^{f x(V)-R}\right]$ and variable emission $E_{p r o}^{\mathrm{var}}$, is the GHG emission from production within the enterprise. $\left[E_{p r o}^{f i x(V)-L}, E_{p r o}^{f i x(V)-R}\right]$ is an interval number, and it represents the possible fixed GHG emission of product family with develop $V$ product variants, and it is mainly from product development, management, etc. In addition, $E_{p r o}^{\mathrm{var}}$ is mainly from product assembly, packing, etc., and it can be formulated as:

$$
E_{p r o}^{\mathrm{var}}=\sum_{m=1}^{M} \sum_{f=1}^{F} \sum_{g=1}^{G} \sum_{h=1}^{H} Q_{f}^{(m)} y_{g h}^{(f)}\left[e_{g h}^{(\text {ass })-\mathrm{L}}, e_{g h}^{(\text {ass })-\mathrm{R}}\right]
$$

where $\left[e_{g h}^{(\text {ass)-L }}, e_{g h}^{\text {(ass)-R }}\right]$ is an interval number, representing the possible GHG emission of assembly for $\mathrm{M}_{\mathrm{m}, \mathrm{n}}$.

$E_{p r o}^{T}$ can be reformulated as follows:

$$
E_{\text {pro }}^{T}=\left[E_{\text {pro }}^{f i x(V)-L}, E_{\text {pro }}^{f i x(V)-R}\right]+\sum_{m=1}^{M} \sum_{f=1}^{F} \sum_{g=1}^{G} \sum_{h=1}^{H} Q_{f}^{(m)} y_{g h}^{(f)}\left[e_{g h}^{(\text {ass)-L }}, e_{g h}^{(\text {ass })-\mathrm{R}}\right]
$$

$E_{\text {sup }}^{\text {sel }}$ is mainly from negotiation communication, relationship maintenance between company and suppliers, etc. It is formulated as follows:

$$
E_{\text {sup }}^{\text {sel }}=\sum_{z=1}^{Z}\left[F_{Z}^{L}, F_{Z}^{R}\right] G_{z}
$$

where $\left[F_{Z}^{L}, F_{Z}^{R}\right]$ represents the possible GHG emission when the $z$ th supplier is adopted.

\subsection{Optimization objectives}

In this article, maximizing the profit is an optimization objectives, and it is formulated as follows:

$$
f_{1}=\operatorname{Max} \Delta=T_{t o}-C
$$

Minimizing the GHG emission is another optimization objectives, and it is formulated as follows:

$$
f_{2}=\min E^{T o}
$$

\subsection{Optimization model constraints}

(1) Configuration constraint

Only one instance can be selected for a function module of a product variant. The configuration constraint is formulated as follows:

(2) Supplier constraint

$$
\sum_{h=1}^{H} y_{g h}^{(f)}=1,(f=1,2, \ldots, F ; g=1,2, \ldots, G)
$$

One module instance of a product variant can be provided by only one supplier, and it can be described as follows: 


$$
\sum_{z=1}^{Z} x_{g h}^{(f) z}=1,(f=1,2, \ldots, F ; g=1,2, \ldots, G ; h=1,2, \ldots, H)
$$

\subsection{Treatment of the uncertain objective function}

In interval mathematics, an uncertain objective function $f_{1}$ can be transformed into the following two optimization problem [14]:

$$
\begin{aligned}
m(f(\tilde{x}, B)) & =\frac{1}{2}\left(f_{1}^{L}(\tilde{x}, B)+f_{1}^{R}(\tilde{x}, B)\right) \\
w\left(f_{1}(\tilde{x}, B)\right) & =\frac{1}{2}\left(f_{1}^{L}(\tilde{x}, B)-f_{1}^{R}(\tilde{x}, B)\right)
\end{aligned}
$$

where $m$ represents the midpoint value, $w$ represents the radius of the interval number, $B$ is the uncertain vector and its components are all interval numbers.

$f_{1}^{L}$ and $f_{1}^{R}$ are calculated as follows [15]:

$$
f_{1}^{L}(\tilde{x}, B)=\min _{C \in \Gamma} f_{1}(\tilde{x}, B), f_{1}^{R}(\tilde{x}, B)=\max _{C \in \Gamma} f_{1}(\tilde{x}, B)
$$

This article adopts the linear combination approach to integrate $f_{1}^{L}$ and $f_{1}^{R}$. It is expressed as:

$$
\begin{aligned}
& f_{1}=k_{1} m\left(f_{1}(\tilde{x}, C)\right)+k_{2} w\left(f_{1}(\tilde{x}, C)\right), \\
& k_{1}, k_{2} \geq 0, k_{1}+k_{2}=1
\end{aligned}
$$

Similarly, the uncertain objective function $f_{2}$ can be expressed as:

$$
\begin{aligned}
& f_{2}=k_{3} m\left(f_{2}(\tilde{x}, B)\right)+k_{4} w\left(f_{2}(\tilde{x}, B)\right), \\
& k_{3}, k_{4} \geq 0, k_{3}+k_{4}=1
\end{aligned}
$$

\section{Solution algorithm}

In this section, the genetic algorithm is developed to solve the proposed optimization model.

\subsection{Chromosome representation}

The integer-coding method is used in this research. A chromosome consists of three sections. Three sections are the product configuration section, supplier selection section, and price selection section. Figure 1 shows the chromosome structure. In product configuration section, the value in gene indicates which module instance is selected. For example, the value is ' 3 ' in the second gene of product configuration section, it represents that the $\mathrm{M}_{2,3}$ is chosen for the second module of product variant 1. In supplier selection section, it indicates the supplier selection. For instance, the value is ' 3 ' in the fourth gene of supplier selection section, and it points out that the third supplier $\left(\mathrm{S}^{3}\right)$ is selected to supply module instance $\left(\mathrm{M}_{1,2}\right)$ for configuring product variant 2 . In this research, the price is discretized in advance. Similarly, the price selected for each product variant is indicated by the gene value in price selection section. 


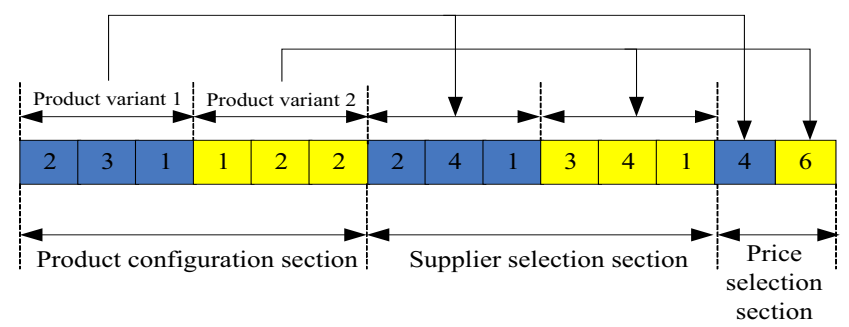

Figure 1. Chromosome structure

\subsection{Fitness function and genetic operators}

The two weights $u_{1}$ and $u_{2}\left(u_{1}+u_{2}=1, u_{1} \geq 0, u_{2} \geq 0\right)$ are assigned to the two objectives, and the weighting method is employed to combine the two objective functions as a fitness function.

In this research, the uniform crossover method [16] is adopted. The mutation operation used in this research is based on the neighborhood. An individual of population mutates with a given probability. The mutation operation is first randomly selection some genes of an individual and then changes these gene values to their neighborhood. The roulette selection method is employed for selection operation in this study.

\section{Case study}

A producer of a radio plans to develop the product family with two product variants. The product has been developed into a modular structure, including product case module (M1), storage module (M2), voice module (M3), key module (M4), control module (M5) and display module(M6). Each module has several candidate modules instances. The three market segments are divided, and the demand of each market segment is estimated, as shown in Table 1. In the market, there are three similar products, and the surplus utilities of similar products are given in Table 1. Table 2 shows the information about module instances. The information of suppliers is shown in Table 4. By analyzing market and cost, the product price is estimated at $[\$ 49.7, \$ 78.8]$. In the case study, the product price is discretized as a set of integer prices from $\$ 50$ to $\$ 80$.

The GA was applied to solve the proposed optimization problem. The population size was set as 2000, and the crossover rate and mutation rate were set as 0.8 and 0.2 , respectively. The related weight is set as follows: $u_{1}=0.7, u_{2}=0.3, k_{1}=0.8, k_{2}=0.2, k_{3}=0.8$, $k_{4}=0.2$. The optimized product configurations and selected suppliers are obtained, and the results are shown in Figure 2. The designer can obtain different optimization results by setting different weights according to their preferences.

Table 1. Utility surpluses (\$) of similar products and market segment size

\begin{tabular}{lrrr}
\hline & Market segment & Market segment 2 & Market segment \\
& $\mathbf{1}$ & & \multicolumn{3}{c}{ 3 } \\
\hline Demand quantity (PCS) & 210,000 & 300,000 & 70,000 \\
Utility of similar product 1 & 62.01 & 59.12 & 64.10 \\
Utility of similar product 2 & 57.06 & 61.05 & 59.00 \\
Utility of similar product 3 & 55.13 & 58.22 & 60.03 \\
\hline
\end{tabular}


Table 2. Related information about module instances

\begin{tabular}{|c|c|c|c|c|c|c|c|c|}
\hline $\begin{array}{l}\text { Modul } \\
\text { e }\end{array}$ & Instance & $\begin{array}{l}\text { Utility } \\
\text { in } \\
\text { segment } \\
1\end{array}$ & $\begin{array}{c}\text { Utility in } \\
\text { segment } 2\end{array}$ & $\begin{array}{c}\text { Utility in } \\
\text { segment } 3\end{array}$ & $\begin{array}{c}\text { Variable } \\
\text { unit cost } \\
\text { (\$) }\end{array}$ & $\begin{array}{l}\text { Variable unit } \\
\text { emission } \\
\text { (g) }\end{array}$ & $\begin{array}{c}\text { Weight } \\
\text { (g) }\end{array}$ & $\begin{array}{c}\text { GHG } \\
\text { emission } \\
\text { (g) }\end{array}$ \\
\hline \multirow[t]{4}{*}{$\mathrm{M}_{1}$} & $\mathrm{M}_{1,1}$ & 16.8 & 15.4 & 15.2 & 0.8 & {$[0.23,0.31]$} & 120 & {$[36.1,37.5]$} \\
\hline & $\mathrm{M}_{1,2}$ & 17 & 15.6 & 15.2 & 0.8 & {$[0.45,0.53]$} & 118 & {$[32.5,34.8]$} \\
\hline & $\mathrm{M}_{1,3}$ & 17.2 & 16 & 16 & 1 & {$[0.28,0.32]$} & 119 & {$[33.2,36.4]$} \\
\hline & $\ldots \ldots$ & $\ldots \ldots$. & $\ldots \ldots$. & $\ldots \ldots$ & $\ldots \ldots$ & $\ldots \ldots$ & $\ldots \ldots$ & $\ldots \ldots$ \\
\hline \multicolumn{8}{|l|}{$\ldots .}$. & \\
\hline \multirow[t]{2}{*}{$\mathrm{M}_{6}$} & $\ldots \ldots$ & $\ldots \ldots$ & $\ldots \ldots$ & $\ldots \ldots$ & ....... & $\ldots \ldots$ & $\ldots \ldots$ & $\ldots \ldots$ \\
\hline & $\mathrm{M}_{6,3}$ & 19.3 & 17.1 & 17.3 & 0.6 & {$[0.24,0.38]$} & 84 & {$[143,157]$} \\
\hline
\end{tabular}

Table 3. Information of suppliers.

\begin{tabular}{clc}
\hline Supplier number & \multicolumn{1}{c}{ Available module instances (purchase price \$)) } & $\begin{array}{c}\text { Distance } \\
(\mathbf{k m})\end{array}$ \\
\hline $\mathrm{S}^{1}$ & $\mathrm{M}_{1,1}(4.8), \mathrm{M}_{1,2}(5.0), \mathrm{M}_{1,3}(5.1), \mathrm{M}_{1,4}(5.3), \mathrm{M}_{3,1}(6.5), \mathrm{M}_{3,2}(6.6), \mathrm{M}_{3,3}(6.6)$ & 681 \\
$\ldots .$. & $\ldots .$. & $\ldots .$. \\
$\mathrm{S}^{13}$ & $\mathrm{M}_{2,1}(10.9), \mathrm{M}_{2,2}(11.2), \mathrm{M}_{2,3}(11.3), \mathrm{M}_{2,4}(11.4), \mathrm{M}_{5,1}(11.8), \mathrm{M}_{5,2}(11.8), \mathrm{M}_{5,3}(11.7), \mathrm{M}_{6,1}(9.9)$, & 925 \\
\hline
\end{tabular}

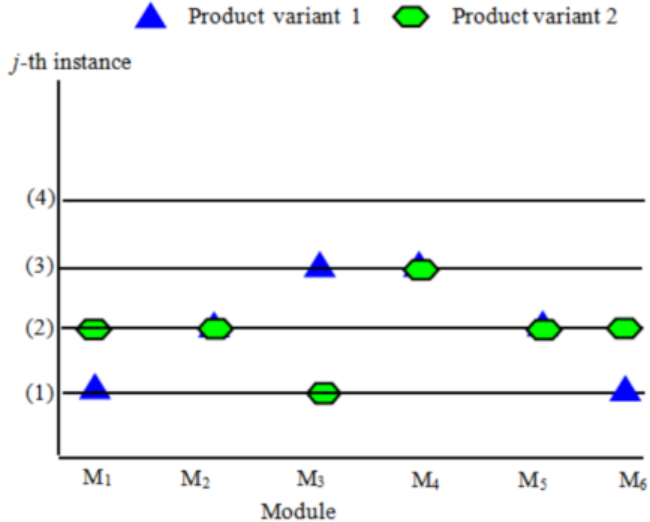

(a) product variant configuration

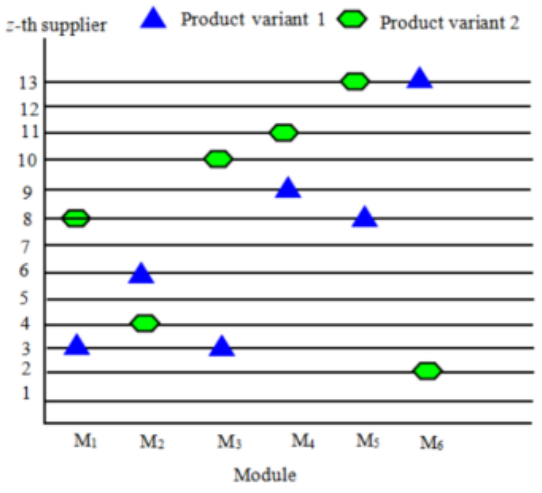

(b) Supplier selection

Figure 2. Optimization results

\section{Conclusion}

In the low-carbon product design, a lot of information is actually uncertain, such as GHG emission information. Previous studies on low-carbon product family 
design did not consider the uncertain design information. This paper proposes a uncertain optimization model for low-carbon product family design. The related uncertain data for low-carbon product family design is expressed as interval numbers. In addition, the genetic algorithm is developed to solve the established uncertain model. Finally, a case study is performed to demonstrate the effectiveness of the proposed approach.

\section{Acknowledgments}

This research was supported by Zhejiang Provincial Natural Science Foundation of China under Grant No. LQ21E050011 and Ningbo Natural Science Foundation (grant No 202003N4316) and Talent introduction Fund Project of NingboTech University (grant No 20191230) and Ningbo philosophy and social planning project (grant No G213-ZX64)

\section{References}

[1] Intergovernmental Panel on Climate Change (IPCC). IPCC Fourth Assessment Report: Climate Change 2007; Working Group III Report “Mitigation of Climate Change” ; 2007, pp. 447-496.

[2] Song, J. S., Lee, K. M. Development of a low-carbon product design system based on embedded GHG emissions. Resources Conservation and Recycling, 2010, 54 (9), 547-556.

[3] Su, J. C. P., Chu, C. H., Wang. Y. T. A decision support system to estimate the carbon emission and cost of product designs. International Journal of Precision Engineering and Manufacturing, 2012, 13 (7), 1037 1045 .

[4] Kuo, T. C. The Construction of a Collaborative Framework in Support of Low Carbon Product Design. Robotics and Computer-integrated Manufacturing, 2013, 29 (44), 174-183.

[5] Xu, Z. Z., Wang, Y. S., Teng, Z. R., et al. Low-carbon product multi-objective optimization design for meeting requirements of enterprise, user and government, Journal of Cleaner Production, 2015, 103, 747758.

[6] Chiang, T. A., Che, Z. H. A decision-making methodology for low-carbon electronic product design, Decison Support Systems, 2015, 71,1-13.

[7] Zhang, C.; Huang, H.H.; Zhang, L.; Bao, H.; Liu, Z.F. Low-carbon design of structural components by integrating material and structural optimization, International Journal of Advanced Manufacturing Technology, 2018, 95, 4547-4560.

[8] Kim, S.; Moon, S.K. Sustainable platform identification for product family design, Journal of Cleaner Production, 2017, 143, 567-581.

[9] Wang, Q., Tang, D., Li, S., Yang, J., Salido, M.A., Giret, A., Zhu, H. An Optimization Approach for the Coordinated Low-Carbon Design of Product Family and Remanufactured Products. Sustainability, 2019, 11,460 .

[10] Wang, Q., Tang, D.B., Yin, L.L., Salido, M.A., Giret, A., Xu, Y.C. Bi-objective optimization for lowcarbon product family design, Robotics and Computer-integrated Manufacturing, 2016, 41, 53-65.

[11] Xiao, W.X., Du, G., Zhang, Y.Y., Liu, X.J. Coordinated optimization of low-carbon product family and its manufacturing process design by a bilevel game-theoretic model. Journal of Cleaner Production, 2018, 184, 754-773.

[12] Wang, Q., Tang, D., Yin, L., et al An optimization method for coordinating supplier selection and lowcarbon design of product family. International Journal of Precision Engineering and Manufacturing, 2018, $19,1715-1726$.

[13] Jiao, J.X., Zhang, Y. Product portfolio planning with customer-engineering interaction. IIE Transactions, 2005,37(9), 801-814.

[14] Ishibuchi, H. and Tanaka, H. (1990). Multiobjective programming in optimization of the interval objective function. European Journal of Operational Research, 1990, 48,219-225.

[15] Jiang, C., Han, X., and et al. (2008). A nonlinear interval number programming method for uncertain optimization problems. European Journal of Operational Research, 2008, 188, 1-13.

[16] Syswerda G., 1989. Uniform Crossover in Genetic Algorithms. In: Proceedings of 3rd International Conference on Genetic Algorithms. San Francisco, USA, pp:2-9. 